\title{
The ethics of wild animal suffering
}

\author{
Ole Martin Moen
}

University of Oslo, Centre for the Study of Mind in Nature

o.m.moen@ifikk.uio.no

DOI: http://dx.doi.org/10.5324/eip.v10i1.1972

This is an open access article distributed under the terms of the Creative Commons
Attribution 4.0 International License, which permits unrestricted use, distribution, and
reproduction in any medium, provided the original author and source are credited.

Animal ethics has received a lot of attention over the last four decades. Its focus, however, has almost exclusively been on the welfare of captive animals, ignoring the vast majority of animals: those living in the wild. I suggest that this one-sided focus is unwarranted. On the empirical side, I argue that wild animals overwhelmingly outnumber captive animals, and that billions of wild animals are likely to have lives that are even more painful and distressing than those of their captive counterparts. On the normative side, I argue that as long as we have duties of assistance towards humans suffering from natural causes, and we reject anthropocentrism, we also have duties of assistance towards animals suffering in the wild.

Keywords: animal ethics, anthropocentrism, duties of assistance, suffering, wildlife

\section{Introduction}

If you have an open wound, a fractured bone, or terminal cancer, you suffer. But how do wounds, bone fractures, and cancers feel for animals such as sparrows, rabbits, and bears? Theoretically, it is possible that it does not feel like anything at all, because animals might not be conscious. Perhaps animals are just complicated machines, more like clocks and cars than like humans. Though it is difficult to establish conclusively that animals really are conscious, however, it is also increasingly difficult to see why rejecting consciousness in animals is any more reasonable than rejecting consciousness in other human beings.

Although solipsism at the species level might make sense within religious contexts where humans are taken to have originated separately from all other animals, it coheres well with neither neuroscience nor evolution. Comparing ourselves to sparrows, rabbits, and bears, we may observe that we have the same kind of neurons, the same main brain parts, and the same pain pathways $(\mathrm{C}$ and $\mathrm{A}$ delta fibers) that they have. Sparrows, rabbits, and bears, moreover, react to noxious stimuli the same way we do, and they stop doing so when anesthetized (see Griffin \& Speck 2004; Dawkins 2015). Since we and other animals are genetically, neurologically, and functionally very close, we would need weighty evidence to conclude that, despite these similarities, humans work in fundamentally different ways from other animals: humans consciously, animals non-consciously. ${ }^{1}$ 
Increased understanding of animal consciousness helped spur the animal ethics movement. Keeping animals in small cages, castrating them without anesthetics, and branding them with glowing irons-practices that, if performed on humans, would land the perpetrator in prison for decades-are common farming practices around the world. Millions of farm animals live and die under such conditions. Opposing human disregard for animal welfare, Peter Singer (1990) famously argues that just as we have gradually expanded our circle of moral concern to encompass ethnic groups other than our own, and finally humanity as a whole, we should further expand it to include other sentient species. According to Singer, it is suffering as such that is bad, and it is bad whoever experiences it.

Though the animal ethics movement is commendable, its circle of moral concern has hitherto expanded almost exclusively to captive animals. With very few exceptions-most notably, David Pearce and Jeff McMahan, whom I shall discuss in detail below-animal ethicists have failed to adequately take into account the suffering of animals living in the wild. Wild animals, however, vastly outnumber captive animals, and arguably, billions of wild animals live lives that are even more painful and distressing than those of their captive counterparts. Though it might well be difficult to alleviate suffering in the wild, and comparatively easier to alleviate suffering caused by humans, disregarding wild animal suffering from the outset involves a form of anthropocentrism that, sadly, enjoys wide acceptance even among those who purport to oppose the doctrine. We might dub this the second anthropocentrism. While traditional anthropocentrics are concerned only with human suffering, anthropocentrics of the second kind are concerned only with human-caused suffering. I will suggest, however, that if we take suffering as such to be bad (roughly along the lines that Singer does), it is unclear why the species membership of those who cause the suffering is morally relevant while the species membership of those who suffer is not.

My aim in this paper is not to sway those who are indifferent to animal welfare. Rather, my aim is to make those who are concerned with animal welfare more concerned with the welfare of wild animals. Moreover, I shall exclusively discuss welfarist concerns, so if there are other grounds to care for animals, they lie beyond the scope of this paper. My discussion is limited to mammals and birds, the reason for which is that these are the animals whose ability to suffer is least disputed. If fish, amphibians, reptiles, and/or invertebrates can also suffer, my conclusion is amplified.

\section{The empirical side}

Let me start by defending three empirical claims: (1) that there are vastly more wild than captive animals; (2) that wild animals have the same capacity to suffer as captive animals; and (3) that many, perhaps most, wild animals suffer at least as much as their captive counterparts. These are all empirical claims that say nothing about the value significance of wild animal suffering. As such, we should accept or reject these claims irrespective of our ethical views.

How many captive animals are there? According to the Food and Agriculture Organization of the United Nations (2014), the total number of livestock in the world is-at any given time-roughly 25 billion, the majority of which are chicken, followed by ducks, cattle, and sheep. Although this figure leaves out pets and 
laboratory animals, let us take for granted, for the sake of convenience, that the number of livestock is roughly representative of the number of captive animals.

How many wild animals are there? According to Brian Tomasik's (2014a) estimations, which are generated from research data on the typical prevalence of various animals in various environments coupled with data on the global prevalence of these environments, there are-at any given time-between 60 and 200 billion birds and between 100 and 1,000 billion mammals. If we assume the middle estimate for both birds and mammals, there are, at any given time, 700 billion wild birds and wild mammals combined. This is roughly 25 times the number of birds and mammals in captivity. (If we were to include in our estimates fish, amphibians, reptiles, and invertebrates, which are rare in human captivity but very prevalent in the wild, we would end up with thousands of times more wild than captive animals.)

A further empirical premise is that wild animals have the same ability to suffer as captive animals. By this I simply mean that if you tear the skin of both a wild and a captive animal, there is no compelling reason to believe that this would hurt more for the captive animal than for the wild animal. In fact, if we were to conclude that there is a difference between the two, we should probably conclude that while captive animals are more docile (due to drugs and lack of stimulation), wild animals remain sharp and focused. Let us assume, however, that the ability to suffer is the same, or roughly the same, in captive and wild animals.

How much do wild animals actually suffer? Very likely, some wild animals suffer very little. Some live long and peaceful lives, have few natural enemies, and have ample supplies of food. When they die, moreover, many animals die quick and painless deaths.

The fact that some lives in the wild are pleasant, however, does not contradict the fact for billions of wild animals, life is filled with suffering. One prominent source of suffering is predation. Every day, millions of animals are eaten alive, and though some of them are killed quickly, larger animals will often stay alive for minutes or hours before they die of blood loss, suffocation, drowning, or internal bleeding from poisoning (Tomasik 2014b). While some become paralyzed, and are likely to feel nothing, others feel excruciating pain.

Predation is a very visible cause of suffering. In response to this, Tyler Cowen (2003) and Jeff McMahan (2010) have argued that if we can easily prevent a predator attack, we have at least a pro tanto moral reason to do so. In their view, the way predators kill their prey is often so gruesome that if a human were to treat animals similarly, we would have strong reasons to intervene - and for the animal that is eaten alive, the species membership of the attacking predator is likely to matter very little.

Though this is an important observation, I think Cowen and McMahan fail to appreciate that suffering caused by predation is likely to account for only a small fraction of the total suffering in nature. Though death from predation might be the most violent and visible cause of suffering, deaths from disease and parasites tend to be more drawn out in time. The same is true of deaths from droughts, floods, and freezing. Life in the wild is also a constant quest for nutrition; at any given time, thousands of animals are in the process of starving to death. Though there is no agent responsible for this suffering, and though it might be hard for us to detect it, the suffering is nonetheless real and prevalent. 
When a parent animal starves or freezes to death, gets eaten, or dies from disease, its young offspring will often face an equally painful death. This borders on an important point, namely that most suffering in nature is likely to be endured by very young individuals. The reason is not primarily that many parent animals die (although that is also the case), but that most wild animals give birth to many more offspring than are likely to reach adulthood. While humans normally give birth to just one child per year, and provide extensive care to each child (this is called the Kselection strategy), many animals follow a different reproductive strategy: they give birth to dozens or hundreds of offspring every year, and care very little for each individual (the $r$-selection strategy). These strategies both work to spread the parents' genes in the population, but the $r$-selection strategy-which is most common in smaller animals-leads to enormous amounts of suffering because of the very large number of young individuals that are left to starve to death or get eaten, either by their stronger siblings or by other predators (for an elaboration, see Horta 2010). If the average female in a given animal population gives birth to 50 offspring every year-and the population size remains stable year after year-then the majority of individuals in that population will be individuals dying before reaching adulthood. If we grant that animals become conscious shortly after birth, as we assume to be the case with humans, their deaths will often involve pain, and since their lives are very short, they will have very few good things in life to weigh up for all that is bad.

For these reasons, Richard Dawkins is almost certainly correct when he writes:

The total amount of suffering per year in the natural world is beyond all decent contemplation. During the minute that it takes me to compose this sentence, thousands of animals are being eaten alive, others are running for their lives, whimpering with fear, others are being slowly devoured from within by rasping parasites, thousands of all kinds are dying of starvation, thirst and disease (Dawkins 1995: 131-32).

Wild animal suffering is mostly invisible to us. Humans never see the vast majority of wild animals, and those that are seen by us are predominantly healthy and moving. We do not see the young individuals starving to death or the adult individuals being devoured by parasites, and we must keep in mind that even if we saw them, their suffering would often not be apparent to us. While we have evolved to pick up pain cues from other human beings, we are much worse at picking up pain cues from non-human animals, especially those that are genetically remote from us. Moreover, many animals hide signs of weakness and disease to avoid attracting predators (including humans) looking for easy prey.

When Thomas Hobbes wrote that life, in the state of nature, is "solitary, poor, nasty, brutish, and short," he meant human life (Hobbes 1651/1996: XIII.9). It seems, however, that the description is also fitting for the lives of many non-human animals.

Because of the brutality of wildlife, one could even make the provocative case that a typical life in the wild is even more painful and distressing than a typical life in human captivity. Although factory farming is often grotesque, animals in captivity are seldom killed in ways that draw out their deaths over several minutes or hours; they are not exposed to predators until they are slaughtered; they typically have access to sufficient amounts of food and water; and the temperature tends to be comfortable. Concerning larger animals, such as cattle, individuals with serious 
diseases will often be euthanized. For this reason, it is not clear that the average life in the wild is filled with any less suffering than the average life in captivity. However, even if wild animals do, on average, suffer less than captive animals, the sheer number of wild animals is still so overwhelming that the majority of suffering on Earth almost certainly takes place among animals living in wild nature.

\section{The normative side}

If the majority of suffering in the world takes place in wild nature: How should we relate to it? As long as we grant that suffering is bad (which seems to be a modest premise), and as long as we further grant that we have a pro tanto reason to help avoid that which is bad, it seems that we have at least a pro tanto reason to help alleviate suffering in the wild. So what might justify our almost total disregard for most of the world's suffering? There seem to be two main kinds of justificatory reasons for our disregard: moral reasons, according to which wild animal suffering should not concern us, even if we could do something about it, and pragmatic reasons, according to which wild animal suffering, though it might be a tragedy, is a tragedy about which we are capable of doing virtually nothing. Let us consider these lines of reasoning in turn.

\section{Moral reasons}

One moral argument in support of the view that wild animal suffering should not concern us is that what happens in the wild is natural and, for this reason, not bad. We might put this argument as follows:

P1: Wild animal suffering is natural suffering.

P2: Natural suffering is not bad.

C: Wild animal suffering is not bad.

The crucial premise in this argument is P2. As it stands, however, this premise is almost certainly false. To see why, it might be instructive to look to parallel cases involving humans, and to observe that although cancers and infections are both natural, we nonetheless think that they are very bad. The question of the naturalness of an event is distinct from the question of its badness.

Consider these two cases: In one case, a man throws a rock at your head and you get a severe pain that lasts for two days. In the other case, an avalanche causes a rock to hit your head and you get a severe pain that lasts for two days. Though there might well be moral differences between the two cases-an agent might be responsible in the former case but not in the latter-the badness of the damage to your head is the same. Thus, if you knew that you had to be subjected to one of the two events, you probably would not care much if an avalanche or a human would be the cause of the rock hitting your head, all else being equal. If this is right, the naturalness of a cause does not seem to affect its degree of badness (or at least, does not affect it very much).

Alternatively, it might be argued that what makes us justified in disregarding wild animal suffering is not specifically that the suffering is natural, but that it happens in the wild part of nature, and that for this reason, "badness," in an ethically relevant sense of the term, does not apply. On this view, although wild nature might well be filled with pain, agony, bloodshed, aggression, hunger, and the 
like, and although these things are very bad when they occur in contexts involving humans, they do not have any ethical significance in wild nature. Ethical terms, we might say, play no role in biology.

In response to this, I concede that, very likely, many ethical terms do not apply to wild nature. Presumably, acts in wild nature can qualify as neither just nor unjust, and there is arguably no such thing as duty, desert, or honesty in groups of nonhuman animals. The fact that some ethical concepts do not apply to wild nature, however, is insufficient to conclude that we should throw out all ethical concepts, including basic evaluative concepts such as "good" and "bad." To see why, it is worth observing that although concepts such as "duty" and "desert" arguably do not apply to what prelinguistic toddlers do to each other, we still think that things can go better or worse for toddlers and that their interests are ethically significant. Most obviously, prelinguistic toddlers can suffer, and even if we reject the view that suffering is the only thing that matters, surely it matters a lot.

Concerning the argument that ethical terms play no role in biology, Jeff McMahan points out that this tells us nothing about whether such terms apply to wild nature:

To suggest [...] that the claim that suffering is bad for those who experience it is "biologically preposterous" [as J. Baird Callicott suggests] makes no more sense than to say that it is mathematically preposterous. The claim that suffering is bad is neither biologically sensible nor biologically preposterous, for it is not a claim about biology at all. Nor does biology have anything at all to say about it. Suffering is of course a biological phenomenon and it occurs in the natural world. But the badness of suffering is not a biological phenomenon. It is nevertheless neither an illusion nor a projection; it too is a part of reality, just not a part that is accessible to the investigative tools of natural science (McMahan 2015: 290).

McMahan's point is that although a discipline such as biology does not employ a set of terms (such as "goodness" and "badness"), this does not imply that other disciplines cannot rightfully employ those terms when studying the same object. This should be a mundane point, for although most of us think that ethical terms do apply to humans and human societies, ethical terms play no role in biological explanations of human behavior and human societies. Ethical terms belong to ethics, and the proper sphere of ethics is not determined by the boundaries of other disciplines.

A different moral argument as to why we may disregard wild animal suffering is that wild animals constitute an out-group with which humans should not interfere. Tom Regan writes:

[T] he total amount of suffering animals cause one another in the wild is not the concern of morally enlightened wildlife management. Being neither accountants nor managers of felicity in nature, wildlife managers should be principally concerned with letting animals be, keeping human predators out of their affairs, allowing these 'other nations' to carve out their own destiny (Regan 1983: 357). ${ }^{2}$

Regan also writes that wild animals "do not need help from us in the struggle for survival.” (Regan 2004: xxxviii; quoted in McMahan 2015) 
Regan's first point, that humans should "let animals be," rests on the premise that animals, as a whole, belong to a distinct group from which humans are excluded. But why should we think that a gazelle is interfered with from something external when a human interferes but by something internal when a tiger interferes? Surely a human and a tiger are equally external to a gazelle. Moreover, as Martha Nussbaum observes, "the death of a gazelle after painful torture is just as bad for the gazelle when the torture is inflicted by a tiger as when it is done by a human being." (Nussbaum 2006: 379)

When we consider the relationship between a gazelle and a tiger, we also see that Regan is wrong in claiming that wild animals "do not need help from us in the struggle for survival." Though it might be true that animal species tend to survive without our help (although that is also only a half-truth, for most species have gone extinct through no fault of humans), at the level of individual animals-which are the ones that can suffer-it is undeniable that in a great many cases, prey do not succeed in their struggle for survival. Moreover, when a gazelle's thighs are ripped to pieces by a tiger, it is strange to claim that what is in the gazelle's best interest is a non-interventionist policy that leaves it and the tiger alone to "carve out their own destiny," as Regan puts it. Why does Regan assume that gazelles are radical libertarians that desire nothing but laissez faire?

Another moral argument against human concern for wild animal suffering is that although what goes on in wild nature can be bad, and although it is not in principle wrong for us to intervene (to, say, help a gazelle from being killed slowly by a tiger), we have very weak or non-existent duties to help. According to this line of argument, we might have a strong duty not to inflict suffering on wild animals, but we do not have a duty to rescue wild animals if their suffering has a different causal origin.

This borders on the more general question of the extent to which we have a duty to prevent, or alleviate, suffering which is not caused by us. Such duties are commonly called duties of assistance. In the case of humans, most accept that we sometimes have strong duties of assistance. For example, in considering Peter Singer's (1972) drowning child example (a child is drowning in a shallow pond and you can save the child at moderate cost to yourself), most agree that we have a duty to save the child. It seems, moreover, that our duty to save the child is as strong, or roughly as strong, if the child slipped and fell into the pond (a natural cause), as it would be if the child were pushed into the pond by a human being who is now unable or unwilling to help.

Let us change Singer's example so that it involves an animal rather than a human. ${ }^{3}$ What if a puppy, rather than a child, was drowning in a shallow pond and you could save it at a low cost? Although we might well have weaker reasons to save the puppy than to save the child (a child might have better reasoning abilities, an ethically more significant emotional repertoire, a mourning family, life plans, and so on), it seems that as long as we reject anthropocentrism (the view that species membership as such is ethically relevant), we cannot draw a sharp line between our duties of assistance towards animals and our duties of assistance towards humans. It seems, moreover, that we should indeed save the puppy drowning in the pond if we could do so at a low cost (our pants would need cleaning, say), even if the puppy fell into the pond by accident and was not placed there by a human. Neither the fact 
that a form of suffering happens in wild nature, nor the fact that it is an animal's suffering, seems to make us justified in simply disregarding it.

\section{Pragmatic reasons}

According to a different line of argument, wild animal suffering might be very bad, and might be bad in a way that has the potential to give rise to duties of assistance. As a matter of fact, however, this line of argument goes, wild animal suffering does not give rise to any duties because there is virtually nothing we can do to prevent it.

One variant of this argument appeals to the precautionary principle. Peter Singer argues:

As for wild animals, for practical purposes I am fairly sure, judging from man's past record of attempts to mold nature to his own aims, that we would be more likely to increase the net amount of animal suffering if we interfered with wildlife, than to decrease it. Lions play a role in the ecology of their habitat, and we cannot be sure what the long-term consequences would be if we were to prevent them from killing gazelles (Singer 1973). ${ }^{4}$

Although I think Singer is wrong in claiming that by intervening, we would be destined to create more net suffering, let us first, for the sake of the argument, assume that he is correct. Would we then be permitted simply to ignore wild animal suffering? I think not. If wild animal suffering is a great evil that we are incapable of stopping, it might be useful to think of our situation as analogous to that of a poor peasant living next to a concentration camp. Would we think that such a peasant, because he is merely a peasant, would be justified in simply ignoring what goes on behind the gates of the camp? If he were made aware of what happens, it seems that he should at least acknowledge that what goes on is very bad and that he should be prepared to act to save escapees should the opportunity ever arise. He should also examine every possible way to help, and he should regularly challenge the assumption that there really is nothing he can do now or that he can prepare to do in the future to help the people in the camp. This is a very different approach from what most of us, animal ethicists included, take toward the suffering of wild animals.

Singer is mistaken, however, in holding that there is nothing we can do to prevent suffering in the wild. First, and most obviously, it is in our power to help individual wild animals. We can help them by feeding them and giving them shelter, or, if they suffer greatly, by euthanizing them. Here it might be objected that although these are heart-warming proposals, such a project is very naive: countless millions of animals are suffering, so helping a few isolated individuals will matter very little. Those who reject anthropocentrism, however, should note that this is not how we tend to think about cases involving humans. When we learn that Oskar Schindler helped individuals escape concentration camps, we do not react by saying that this was probably not worth the trouble since so many millions were not saved. The reason we do not react this way is that for those who were in fact saved, being saved meant everything, irrespective of how many others were not saved. Recall the famous starfish story, where a man encounters a woman on the beach who, after a storm, helps stranded starfish back into the sea:

'Excuse me Miss, but why are you wasting your time? There are thousands of stranded starfish and miles of beach. Are you crazy? You can't possibly 
make a difference!' The woman paused for a moment; thoughtfully looked at the stranger and then down at the starfish she cradled delicately in her hand, before turning away and gently tossing the starfish back into the surf. Looking back at the stranger she said, 'Sure made a difference to that one.' (Eiseley 1972: 63)

As long as we reject anthropocentrism, it is hard to make the case that helping individual animals is not worthwhile. Though the question of the number of other suffering individuals is relevant to questions of resource allocation (since it might be better to help other individuals instead), it is difficult to see how the number of other animals suffering lowers the value of saving one animal from an otherwise painful death.

Concerning interventions on a larger scale, we must certainly proceed with great caution. Still, Singer's comparison with earlier human interventions is not entirely fair, for even though it is true that humans have harmed animals on a large scale in the past, this need not speak to human inefficiency or folly, since it has virtually never been our goal to avoid harm to animals. If avoiding harm to animals had been our aim, chances are that we would have been much more successful in achieving it.

How might we intervene to alleviate wild animal suffering on a large scale? To approach an answer to this question, let us first consider a very naive solution: Bombing the forests with aspirin. Although doing so would presumably alleviate some pain in the short term, it would almost certainly not be advisable, for it would disturb the lives of the animals affected in ways that could leave them in an even worse condition after the pharmacological effect wore off. The aspirin solution, therefore, is clearly vulnerable to Singer's objection that intervention is likely to create more harm than good.

Although no one has defended the aspirin solution, other solutions have been suggested. Jeff McMahan argues that, in the future, it might be possible and advisable to turn carnivores into herbivores through genetic engineering (McMahan 2010). Though this proposal would only help end suffering caused by predation (which I suggest is only a small fraction of the total suffering in nature), the proposal is an interesting one since, presumably, ending predation would help reduce net suffering, and it is not far-fetched to alter dietary preferences through genetic engineering. What is more far-fetched is to make post-carnivores thrive on a radically different diet and to make sure that the absence of predators will not lead to a Malthusian explosion in the populations of other animals whose lives will consequently be very bad.

David Pearce has put forth an even more radical solution: that as technology advances, we should aim, ultimately, to use bio- and nanotechnology to intervene in wild animals' central nervous systems, altering them such that their pleasure/pain mechanism is replaced by a mechanism that, phenomenally, consists purely of gradients of bliss. In Pearce's view, a gradients-of-bliss mechanism could, in theory, be functionally identical to a pleasure/pain mechanism, and could guide animals to act as they do today without the raw, phenomenal pain that Darwinian evolution has instilled in us (Pearce 1995). The technologies required to carry out Pearce's plan are even further beyond reach than the technologies required by McMahan's. Pearce's plan, moreover, includes what seems to be an unnecessary complexity, for if there ever comes a time when we can micromanage nature the way Pearce hopes, then why would we make sure that animals act the way they do today? If our aim is 
to eliminate suffering, it seems that this could be done in far simpler ways than by replacing the pleasure/pain mechanism with a functionally identical gradients-ofbliss mechanism. This borders on another solution discussed by Pearce, more as a thought experiment than as a suggestion. Pearce asks: If we could push a button that, quickly and painlessly, destroyed all sentient life, should we push it? Although the idea is repulsive to most, according Pearce, ending the lives of billions of happy animals could be a price worth paying to bring all the world's suffering to an end (Pearce 2015).

Although any means to bringing about a large-scale reduction in wild animal suffering is bound to be radical and futuristic, let me here sketch what I think is likely to be the least problematic strategy. That strategy would be to drastically reduce the number of sentient animals living in the wild while preserving members of all species in large wildlife parks where the worst forms of suffering can be avoided. Let us call this the Noah's Ark Suggestion. My aim in the following is to outline and give a partial defense to this suggestion. The defense is partial because my aim is not to argue that this suggestion should be put into practice. My aim, more modestly, is to provide an example which illustrates that we are not justified in simply assuming that there is nothing we can do, now or in the future, to reduce wild animal suffering. I shall sketch and defend the suggestion in response to a number of objections.

One objection to the Noah's Ark Suggestion is that in order to implement it, we would-as in the case of pushing Pearce's button and, indeed, as in the case of the mythological Noah's Ark-need to kill enormous numbers of animals, billions of which would be likely to have lives worth living. The proposal, one might say, would involve a partial button pushing, which is also an extreme measure. There are two ways to respond to this objection. One response is that it might be worth it, for although killing healthy animals would indeed be an extreme measure, wild animal suffering is an extreme problem, and so it might be worth paying a very high price to bring it to an end. It is interesting to note, moreover, that we seldom think that animals are harmed much by being killed as long as they are killed painlessly. Humans kill millions of animals every day, the central ethical objection to which is not merely that animals are killed, but that many of them suffer greatly before they are killed (pace McMahan 2002). Accordingly, if sufficiently many wild animals have sufficiently bad lives, killing some animals with good lives might be worth it.

To illustrate this, imagine that you are witnessing a barn on fire. Inside are 20 cows. You now have only two options: One option is to do nothing, which will result in 10 cows escaping the barn unharmed while the remaining 10 cows will burn to death in agony. The other option is to kill all 20 cows instantaneously (with a poisonous gas, say). Should you kill them all or should you do nothing? If it is a tragedy that a cow burns to death, but not a tragedy that a cow is painlessly killed, then a weighty reason counts in favor of killing all 20 cows. If this is right, we cannot rule out strategies that involve killing more animals than just those that are suffering.

Another reply is to point out that drastically reducing the size of wildlife populations can be achieved without any killing at all: It can be achieved by drastically limiting reproduction. If we could sterilize animals on a large scale (and, before we did so, could confine sufficient numbers to wildlife parks), we could phase out wild populations without killing a single animal. Admittedly, it is true that this 
approach would result in future animals that could have had good lives in the wild never being born, but this is presumably a much smaller loss, since there would be no animals to miss out on these potential goods. Presumably, no one is harmed by never being born.

Another way to challenge the Noah's Ark Suggestion is to appeal to environmental reasons. One such reason is that we might endanger species by holding them in wildlife parks. This is potentially a good objection. It is not clear, however, that species are valuable even apart from the well-being of its members, but if they were, we could presumably make wildlife parks even safer than wild nature if we apply modern reproductive technologies where necessary and cryopreserve eggs, sperm, and embryos as backup. While many species go extinct in wild nature, few species that humans actively seek to protect suffer the same fate.

A different argument might be that the quality of life for the animals living in wildlife parks would be very low. Perhaps these animals would have a thwarted development, and would be constantly frustrated due to not being able to act on their instincts. If the wildlife parks are large and varied, however, and are located in the animals' natural habitats, it seems that most of the animals would be able to live lives almost as they would otherwise have done, but absent the most extreme and unnecessary suffering that takes place so frequently in unregulated nature. Unless we think that a life is made good simply by virtue of being natural, it seems that animals would have, on balance, much better lives in wildlife parks than in the wild.

A third environmental objection might be that by eradicating large portions of wildlife, we would create environmental instability. In considering this objection, it is important to keep in mind, first, that an intervention in nature is not an intervention in a harmonious system, but an intervention in a warzone. As such, animals do not start dying if such a system gets destabilized (they do that in enormous numbers anyway), but different individuals die than would otherwise have died. It is not clear that this worsens the situation. In the long run, moreover, the difference would not be great at all, since within two or three decades, virtually all of the animals that were alive would have died anyway. The destabilization only leads to different timings of the deaths of the various animals. A second thing to keep in mind is that if the phasing out is sufficiently extreme, it becomes less of an environmental problem. If no wild wolves exist, their population will not be negatively affected by there being no wild rabbits. The central problem would be the effect on humans, who seldom starve and get eaten at young age, and who, presumably, tend to have lives worth living. There is no reason to believe, however, that nature would collapse without wild variants of the animals that we discuss in this paper. Ecosystems have existed on Earth for millions of years without the socalled "higher" animals. While it is true that the "top" cannot exist without the "bottom," the "bottom" can exist well without the "top," and has done so throughout most of Earth's history.

Finally, it might be suggested that preserving nature has intrinsic value, and that this counts against the Noah's Ark Suggestion. But how far does this objection get us? Earth has undergone radical changes throughout its 3.5 billion year history, and as such, it would be curious if it had just now reached the state that is intrinsically valuable and ought to be preserved in perpetuity. If what has intrinsic value is not its current state, however, but the very existence of nature (and perhaps the existence of many different species), this will remain unaffected by the Noah's Ark Suggestion. A 
somewhat different variant of the argument might appeal to nature's current aesthetic value. It is unclear, however, how much the world's aesthetic value would decrease if we confined higher animals to wildlife parks. All non-living things (oceans, lakes, mountains, etc.) and most plants would remain intact. So would the animals, although they would be restricted to areas where their most intense and unnecessary suffering could be avoided. Even if the proposal would involve some loss in aesthetic value, however, it is not at all clear that we are justified in letting billions of animals suffer for the sake of avoiding an aesthetic loss.

\section{Conclusion}

The suggestion that we should take wild animal suffering seriously as an ethical issue runs contrary to many of our most powerful biases. It concerns animals for which we, instinctively, feel very little sympathy, and whose suffering we humans did not cause and thus do not feel obliged to help alleviate. The suffering is also far removed from our daily lives and it exists on a scale of magnitude so large that it is hard for us to grasp it. Finally, wild animal suffering challenges a romantic view of nature, which is deeply held by many, and since all large-scale solutions lie far in the future, it is easy for us simply to disregard it.

When we correct for our biases, however, it becomes difficult to justify our disregard. This might most obviously be the case for utilitarians, who hold that we should be concerned with alleviating suffering irrespective of where it takes place and what caused it. Utilitarianism, however, is not the only ethical theory that obliges us to take wild animal suffering into account; to the extent that other theories also oblige us to care about animal welfare, and ascribe to us duties of assistance, adherents to these theories should also care about animals suffering in the wild, albeit perhaps to a lesser extent than utilitarians do. Indeed, it is hard to see how any ethical theory-with the exceptions of egoism, strict anthropocentrism, and the idea that all that is natural is good-could permit us to ignore wild animal suffering the way the topic is currently ignored. Here it is also interesting to note that although caring about wild animal suffering might seem alien from a Western, Judeo-Christian point of view, other intellectual traditions view these matters very differently. Buddhism, Hinduism, and Jainism, for example, all hold that the natural world is filled with suffering, that suffering is bad for all who endure it, and that our ultimate aim should be to bring suffering to an end. In this respect, these worldviews seem more apt than the Judeo-Christian world-view, according to which the natural world, being designed by God, is in fundamental harmony.

Which steps can we take to reduce suffering among wild animals? First of all, we can help individual animals by feeding them and giving them shelter, by giving them basic veterinary care, and-if they are very ill-by euthanizing them. Another small step is to stop so-called rewilding projects. Some prominent environmentalists, such as E. O. Wilson (2014), argue that half of the Earth should be rewilded. Others, like George Monbiot (2013), defend rewilding on a smaller scale, and several wildlife groups now work actively to reintroduce animals such as wolves, beavers, and lynx in places where they have been extirpated. Such programs should be brought to an end. Rewilding causes great amounts of unnecessary suffering, and ending these programs is very cheap; the programs are costly, so if we stop them, we will be left with more wealth, not less, to pursue other goals. 
Our primary aim, however, should be to get wild animal suffering on the research agenda, and to make sure that it is taken into account in the development of future technologies. Future technologies are our only hope for reducing wild animal suffering on a large scale, whether through wildlife parks or through other means. We should also make sure that by introducing new technologies, we do not increase wild animal suffering. If we engage in terraforming and spreading life to other planets, we might easily create enormous amounts of suffering in man-made, yet unregulated, nature.

One way to increase the chances that the suffering of wild animals will be taken into account in research and development is to challenge the biases and assumptions that make it so difficult for us to address it. Most important, perhaps, is the pre-Darwinian fiction that life in nature is harmonious, and that without human intervention, all is fine and good. The truth is quite the opposite. If we imagined that from now on, animals started emitting a red light every time they suffered, then from space, Earth would no longer be a blue planet, but a red and glowing one.

\section{Notes}

${ }^{1}$ This is not to deny that certain forms of suffering, such as fear of death or the feeling of meaninglessness, might presuppose distinctly human abilities, such as language. It is not clear, however, how much that detracts from animals' overall ability to suffer. Note that in the case of prelinguistic toddlers, we do not assume that their lack of language skills makes their suffering less intense.

${ }^{2}$ Gary Francione holds a very similar view, suggesting that "we should simply leave them alone." (Francione 2008: 13).

${ }^{3}$ Thanks to Francesca Minerva for suggesting this example.

${ }^{4}$ Later, Peter Singer has written that we "do enough if we eliminate our own unnecessary killing and cruelty towards other animals." (Singer 1990: 227) Although I will not pursue this suggestion further here, it is unclear how Singer, granted that he is a maximizing utilitarian, can hold that a certain level of assistance is "enough," other than by this level being the optimal level. Interestingly, however, Singer now appears to have changed his mind regarding wild animals, albeit not in print (Singer 2015). Thanks to an anonymous reviewer for pointing this out.

\section{References}

Cowen, T. (2003). Policing Nature. Environmental Ethics 25: 169-182. http://dx.doi.org/10.5840/enviroethics200325231

Dawkins, M. S. (2015). Animal welfare and the paradox of animal consciousness. Advances in the Study of Behavior 49: 5-38. http://dx.doi.org/10.1016/ bs.asb.2014.11.001

Dawkins, R. (1995). River Out of Eden. New York, NY: Basic Books.

Eiseley, L. (1972). The Star Thrower. In The Unexpected Universe. Orlando, FL: Mariner Books.

Food and Agriculture Organization of the United Nations (2014) Live animals. Retrieved February 10, 2016, at http://faostat.fao.org/site/573/Desktop Default.aspx?PageID=573\#ancor 
Francione, G. (2008). Animals as Persons. New York, NY: Columbia University Press.

Griffin, D. R \& Speck, G. B (2004). New evidence of animal consciousness. Animal Cognition 7: 5-18. http://dx.doi.org/10.1007/s10071-003-0203-x

Hobbes, T. (1651/1996). Leviathan. Cambridge: Cambridge University Press.

Horta, O. (2010). Debunking the Idyllic View of Natural Processes: Population Dynamics and Suffering in the Wild. Telos 17: 73-90.

McMahan, J. (2010, September 19). The Meat Eaters. New York Times.

McMahan, J. (2015). The Moral Problem of Predation. In Andrew Chignell, Terence Cuneo \& Matthew C Halteman (Eds.), Philosophy Comes to Dinner: Arguments About the Ethics of Eating. London: Routledge, pp. 268-294.

Monbiot, G. (2013). Feral. London: Allen Lane.

Nussbaum, M. (2006). Frontiers of Justice: Disability, Nationality, Species Membership. Cambridge, MA: Belknap Press.

Pearce, D. (1995). The Hedonistic Imperative. Retrieved February 11, 2016, from http://www.hedweb.com/hedethic/tabconhi.htm

Pearce, D. (2015). Unsorted postings. Retrieved December 10, 2015, from http://www.hedweb.com/social-media/pre2014.html

Regan, T. (1983). The Case for Animal Rights. Berkeley, CA: University of California Press.

Regan, T. (2004). The Case for Animal Rights. New preface edition. Berkeley, CA: University of California Press.

Singer, P. (1972). Famine, Affluence, and Morality. Philosophy and Public Affairs 1:229-243. http://dx.doi.org/10.1017/S0031819102000438

Singer, P. (1973, June 14). Food for Thought. New York Review of Books.

Singer, P. (1990). Animal Liberation. 2nd edition. London: Cape.

Singer, P. (2015). Predation. Retrieved February 17, 2016, from https://www.youtube.com/watch?v=rrhBJlxKqyA

Tomasik, B. (2014a). How Many Wild Animals Are There? Retrieved October 20, 2015 from http://reducingsuffering.org/how-many-wild-animals-are-there/

Tomasik, B. (2014b). Wild Animal Suffering. Retrieved October 212015 from http://foundational-research.org/the-importance-of-wild-animal-suffering/

Wilson, E. O. (2014). The Meaning of Human Existence. New York, NY: Liveright. 